\title{
Feeding behavior of Triatoma vitticeps (Reduviidae: Triatominae) in the state of Minas Gerais, Brazil
}

\author{
Rita de Cássia Moreira de Souza', Adriana C Soares², Ceres Luciana Alves², \\ Elias Seixas Lorosa ${ }^{3}$, Marcos Horácio Pereira², Liléia Diotaiuti ${ }^{1 /+}$
}

'Laboratório de Triatomíneos e Epidemiologia da Doença de Chagas, Instituto René Rachou-Fiocruz, Av. Augusto de Lima 1715, 30190-002 Belo Horizonte, MG, Brasil

${ }^{2}$ Departamento de Parasitologia, Instituto de Ciências Biológicas, Universidade Federal de Minas Gerais, Belo Horizonte, MG, Brasil ${ }^{3}$ Laboratório Nacional e Internacional de Referência em Taxonomia de Triatomíneos, Instituto Oswaldo Cruz-Fiocruz, Rio de Janeiro, RJ, Brasil

The objective of this study was to evaluate the feeding behavior of Triatoma vitticeps through the identification of its food sources and the characterization of the blood ingestion process. In addition, we aimed to verify if the saliva of this vector interferes with the perception of the host during the feedings by creating a nervous impulse. Here, we demonstrated that the T. vitticeps saliva reduces, gradually and irreversibly, the amplitude of the compound action potential of the nervous fibre, which helps decrease the perception of the insect by the host. The precipitin reaction demonstrated the feeding eclecticism of this vector, with the identification of eight food sources - most of them found simultaneously in the same insect. The analysis of the electrical signals produced by the cibarial pump during meals demonstrated that the best feeding performance of $\mathrm{T}$. vitticeps nymphs that fed on pigeons is mainly due to the higher contraction frequency of the pump. The longer contact period with the host to obtain a complete meal compared with other triatominae species of the same instar could favor the occurrence of multiple blood sources in $\mathrm{T}$. vitticeps under natural conditions, as it was evidenced by the precipitin test.

Key words: hemiptera - feeding behavior - saliva - cibarial pump - hematophagic

Triatoma vitticeps is a triatominae species found in the Brazilian states of Espírito Santo (ES), Minas Gerais $(\mathrm{MG})$, Rio de Janeiro (RJ) and the southernmost regions of Bahia (Lent \& Wygodzinsky 1979, Silveira et al. 1984). Studies carried out on T. vitticeps populations in ES, RJ and MG demonstrated the capacity of this triatomine to invade houses (Santos et al. 1969c, Ferreira et al. 1986, Sessa \& Carias 1986, Dias et al. 1989, Gonçalves et al. 1998, Souza et al. 2008). Similarly, these invasive insects were always highly infected with flagellates similar to Trypanosoma cruzi (Pinto et al. 1969, 1986, Santos et al. 1969a, b, Barros et al. 1975, Sessa \& Carias 1986, Dias et al. 1989, Gonçalves et al. 1998, dos Santos et al. 2005, 2006). On the other hand, colonization is not efficient and several studies on the feeding habits of this triatomine using the precipitin method demonstrated some difficulty to obtain a full meal.

The life cycle and population dynamics of triatominae species are directly related to their interaction with vertebrate hosts (Schofield 1994). The host's ability to perceive the insect during the feeding process represents a threat to the insect and may determine its success in obtaining blood. When the vertebrate host notices the presence of the insect, it attempts to eliminate it me-

Financial support: UNDP/World Bank/WHO/TDR, FIOCRUZ, CNPq, FAPEMIG

+ Corresponding author: diotaiuti@cpqrr.fiocruz.br

Received 5 May 2010

Accepted 12 August 2010 chanically, which can cause an early interruption of the feeding or even the insect's death (Rossignol et al. 1985). Species in the subfamily Triatominae minimize such a threat with two cooperative mechanisms: the production of a salivary anaesthetic (Dan et al. 1999) and the development of an efficient muscular pump (the cibarial pump), which is capable of generating high pressures that allow the ingestion of large quantities of blood in a short period of time (Bennet-Clark 1963). In these vectors, the contact time with the hosts is influenced by the blood ingestion rate, which varies among triatomine species, the developmental stage and the physiology of the host (Guarneri et al. 2000, 2003, Sant'Anna et al. 2001).

The identification of the food source of hematophagous insects is highly used for epidemiological studies of infectious diseases to find the vectorial potential presented by the insects in various diseases, such as the Chagas disease. In 1960, Siqueira (1960) demonstrated that it was possible to find, through the precipitin reaction, the feeding source of triatomines kept under laboratory settings, even when the blood ingestion had occurred 120 days earlier. Using this technique, Dias et al. (1989), Gonçalves et al. (2000) and Lorosa et al. (2003) demonstrated that $T$. vitticeps have a significant feeding eclecticism, a fact of great epidemiological importance because a $T$. cruzi infection may derive from different sources.

The occurrence of multiple blood meals in T. vitticeps might be the result of the unfeasibility to obtain a full meal from a single source. Therefore, information about how the perception of the host can interfere with the feeding process of $T$. vitticeps would be fundamental to understand the aspects related to the feeding behavior of $T$. vitticeps. In addition, the identification of the 
feeding sources, the dynamics of blood ingestion and the generation of in vitro nerve impulses triggered by the vector's saliva to assess the interference of the hosts' perception are of crucial importance.

\section{MATERIALS AND METHODS}

The insects - The T. vitticeps used in this study derived from the Itanhomi district $\left(1^{\circ} 11^{\prime} 15^{\prime \prime} \mathrm{S}, 41^{\circ} 48^{\prime} 45^{\prime \prime} \mathrm{W}\right)$, located at $387 \mathrm{~km}$ from Belo Horizonte, MG. For the identification of the feeding sources, insects captured by health agents were used, as well as insects notified by the local population. For the study of the saliva and the monitoring of the cibarial pump, the insects were reared in the laboratory under controlled conditions of temperature $\left(27 \pm 2^{\circ} \mathrm{C}\right)$ and humidity $(60 \pm 10 \%)$.

Identification of the feeding sources - The 89 specimens of $T$. vitticeps analyzed were adults. Of these, 82 were derived from the intra and peridomicile areas (barns and basements), while seven were captured from light traps in the silvatic environment through luminous trap. Samples of the stomach contents of live insects were directly impregnated in filter paper. When the insects were dead and the stomach contents were dried, they were dissected and the extracted material was eluted in $1 \mathrm{~mL}$ of saline solution before its absorption with filter paper. After the papers were dried, they were wrapped in aluminium foil and stored individually at $-20^{\circ} \mathrm{C}$. For the precipitin test, the antisera preparation, the titers determination and the specificity were performed according to Lorosa et al. (1998). The blood sources investigated were the probable hosts that occur in the study area. We used the following antisera: human (1:15.000), rodent (1:15.000), bird (1:10.000), opossum (1:12.000), lizard (1:8.000), dog (1:15.000), cattle (1:13.000) and armadillo (1:10.000).

Action of T. vitticeps saliva - The saliva was individually collected with a capillary tube by the mechanical stimulation of adult insects and 5th instar nymphs 15 days after feeding. We used 30 insects to extract saliva. The saliva discharged was transferred to a microtube and kept in ice to form a pool of saliva. The extraction was performed on the day before the experiment and it was maintained at $-20^{\circ} \mathrm{C}$ until use.

The experiments were performed on the sciatic nerve of the Wistar strain and the compound action potentials were recorded using the single sucrose-gap method, as described by Cruz et al. (1994). The nerves were carefully removed, desheathed and placed across the five compartments of the experimental chamber, on a narrow groove sealed with vaseline to isolate the compartments and to mechanically secure the nerve bundle. The first two compartments were used for supramaximal stimulation at a frequency of $0.1 \mathrm{~Hz}$. The central compartment, containing $200 \mu \mathrm{L}$ of the test solution, was grounded and electrically isolated from the 5th (recording) compartment through which a $282 \mathrm{mM}$ sucrose solution constantly flowed. The other compartments were filled with Locke's solution, which contained (in $\mathrm{mM}$ ): $154 \mathrm{NaCl}, 5.5 \mathrm{kCl}, 2.2 \mathrm{CaCl}_{2}, 5.0 \mathrm{~N}$ (2-hydroxyethyl) piperazine-N'- [2-ethanesulphonic acid (HEPES)], 5.0 glucose and the $\mathrm{pH}$ was adjusted to $7.5 \mathrm{using}$ $\mathrm{NaOH}$. Compound action potential amplitudes $>35 \mathrm{mV}$ were routinely recorded and remained stable for more than $5 \mathrm{~h}$ after stabilization of the recording conditions $( \pm 1 \mathrm{~h})$. The electrodes placed in the test and the 5th compartments were fed into a differential amplifier with fixed gain (50 times). The resulting electrical signal was then collected via a digital data acquisition plate $\left(\mathrm{ADC} 100^{\circledR}\right.$-Pico Technology Limited, UK) and stored in an IBMAT compatible microcomputer for subsequent off-line analysis.

Feeding behavior - For this experiment, we selected 2nd instar nymphs of T. vitticeps with approximately 12 days of fasting after molting. This instar was selected because of its shorter time to obtain a full meal. Pigeons and hairless mice were used as feeding sources. The mice were anesthetized intraperitoneally with a mixture of Ketamine and Xylazine (Agener União; 150 and $10 \mathrm{mg} /$ $\mathrm{kg}$, respectively). Twenty insects were individually allowed to feed on the abdominal region of the mice. For the pigeon assays, the birds were immobilized and 20 insects were individually allowed to feed on a small area of the breast from which all feathers had been removed. Care was taken to minimize light, odor, noise and vibrations when handling the insects before testing.

The feeding process was analyzed through a monitoring system of the electrical activity of the insects' cibarial pump developed from the Smith's technique (Smith 1979) and modified by Guarneri et al. (2003). One electrode was fixed to the host and a 2nd electrode was connected to a metal mesh, which was fixed to a container used as substrate for the insects. These two electrodes detected the electrical signals from the cibarial pump. The signals were filtered to reject frequencies above $17 \mathrm{~Hz}$ (with a slope of $45 \mathrm{~dB} /$ octave), amplified 200 times and collected via a digital data acquisition plate (ADC100 ${ }^{\circledR}$-Pico Technology Limited, UK) connected to an IBMAT compatible microcomputer. The electrode and the metal mesh were moistened with an electrolytic gel (Regisgraf-Gel ${ }^{\mathbb{R}}$ ) to facilitate the passage of the electrical signals. To determine weight gain, the insects were weighed immediately before (initial weight) and after feeding. Each insect was allowed to feed until it removed its mouthparts without trying to probe again within $1 \mathrm{~min}$. The engorgement phase was considered to start after at least 10 consecutive characteristic peak-like signals attributed to the cibarial pump contractions.

From the cibarial pump records, the total contact time was defined as the time during which the insect mouthparts remained inserted into the host skin. The non-ingestive time, the initial cumulative probing time and the interruption time were also determined. The non-ingestive time was defined as the time when insects were not pumping, so probing time plus any interruption to feeding comprised this time. The cumulative probing time was defined as the sum of the times from the 1st insertion of the mouthparts into the host up to the beginning of the engorgement phase. If the bug ended an initial probing and restarted another one elsewhere, the 1st probing time was added to the 2 nd and so successively. The last probing time was the time from the last bite until the start of the engorgement phase. The interruptions were defined as stops for more than $4 \mathrm{~s}$ in blood pumping after the engorgement phase had begun. The interruption time was 
defined as the sum of all the individual interruption times. The pump frequency was defined as the total number of cibarial pump contractions divided by the effective contact time (i.e., the time in which the pump was effectively working, without probing or interruptions). The total ingestion rate was calculated by dividing the weight gain by the total contact time and the effective ingestion rate by dividing the weight gain by the effective contact time. The number of bites per insect was also counted.

Software that works under a Matlab (version 6.5.0) environment was developed to analyze the records of the electromyogram of the cibarial pump. This software enables the analysis of the frequency spectrum from the signals generated by the cibarial pump in relation to the time of feeding (Araujo et al. 2009). The results were analyzed with the Kolmogorov-Smirnov test to evaluate if the distribution of each variable was normal. The variables were then compared through the Student $t$ test. The statistical significance was determined at $\mathrm{p}<0.05$.

\section{RESULTS}

Study of the feeding source - The results of the blood meal identification were based on 89 specimens. From these, 21 were no reactive to the antisera tested, 43 (48.3\%) reacted to a single source, $20(22.5 \%)$ reacted to two sources and five $(5.6 \%)$ reacted to three different sources. When the insects fed on more than one host, two or more sources of blood could be found in a single insect sample. Our data suggest that the most frequent association, considering all the samples, was birds and rodents blood (7.9\%) (Table I). By grouping the insects that fed on a single source with those that fed on two or more, the rodents' blood prevailed, totalizing 36 samples (30\%), followed by birds' blood $(25 \%)$, found in 30 of the processed samples (Table II).

The origin of the ingested blood and the percentage of positive reactions to its respective antisera are shown in Table II. The identification of the blood meals showed that the rodents are the main food source in the three studied environments. The birds were the 2 nd most common food source in domestic and peridomestic habitats. In the forested surroundings, the armadillo was also a feeding source for this vector. However, its anti-serum was only available for part of the insect samples. Human blood appears only at the intra-domicile area with $9 \%$ of the reactions.

Action of the saliva of $T$. vitticeps on the generation of nerve impulses - The addition of $1 \mu \mathrm{L}$ of T. vitticeps saliva in the preparation of the nerve produced a progressive reduction of the amplitude of the compound action potentials, without showing alterations on the repolarization phase when compared to the control. Fig. 1A illustrates one of the four replicas of this experiment. No recovery of the compound action potential amplitude was observed even 30 min after washing the preparation with Lock's solution. The mean reduction observed was $66.1 \% \pm 6.3(\mathrm{n}=4)$ (Fig. 1B).

Dynamics of blood ingestion: electrical monitoring of the cibarial pump - The nymphs of T. vitticeps that fed on mice showed a lower mean blood ingestion rate than the rate observed in pigeons and it was mainly due to the lower contraction frequency of the cibarial

TABLE I

Feeding sources identified by the reaction of precipitin in specimens of Triatoma vitticeps captured and notified in the district of Itanhomi, Minas Gerais, Brazil

\begin{tabular}{|c|c|c|}
\hline $\begin{array}{l}\text { Feeding } \\
\text { sources }\end{array}$ & Hosts & $\begin{array}{l}\text { Total } \\
\mathrm{n}(\%)\end{array}$ \\
\hline \multirow{7}{*}{1} & Rodent & 17 (19.1) \\
\hline & Bird & $15(16.8)$ \\
\hline & Cattle & $1(1.1)$ \\
\hline & Opossum & $6(6.7)$ \\
\hline & Dog & $2(2.2)$ \\
\hline & Human & $1(1.1)$ \\
\hline & Armadillo & $1(1.1)$ \\
\hline \multirow{9}{*}{2} & Bird/human & $1(1.1)$ \\
\hline & Bird/rodent & $7(7.9)$ \\
\hline & Bird/dog & $3(3.4)$ \\
\hline & Dog/human & $2(2.2)$ \\
\hline & Dog/rodent & $1(1.1)$ \\
\hline & Opossum/rodent & $1(1.1)$ \\
\hline & Human/rodent & $3(3.4)$ \\
\hline & Lizard/rodent & $1(1.1)$ \\
\hline & Rodent/armadillo & $1(1.1)$ \\
\hline \multirow{3}{*}{3} & Bird/opossum/rodent & $1(1.1)$ \\
\hline & Bird/dog/rodent & $3(3.4)$ \\
\hline & Dog/human/rodent & $1(1.1)$ \\
\hline Did not react & & $21(23.6)$ \\
\hline Total insects & & 89 (100) \\
\hline
\end{tabular}

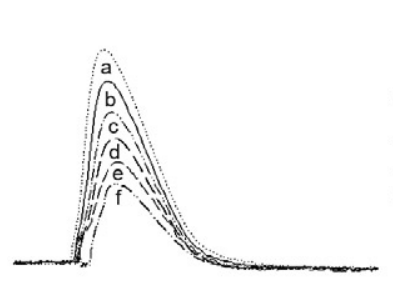

A

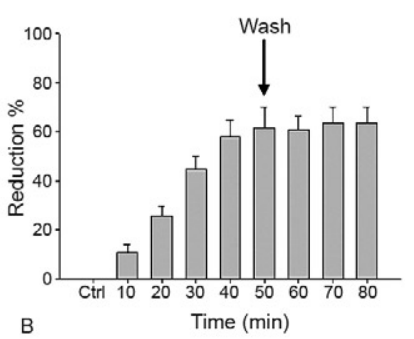

Fig. 1A: effect of $1 \mu \mathrm{L}$ of Triatoma vitticeps saliva on compound action potential of rat sciatic nerve. The compound action potentials were obtained in control condition (a) and after incubation with the saliva (b, 10; c, 20; d, 30; e, 40; f, $50 \mathrm{~min}$ ). Records were superimposed to allow better comparison; B: percentage of activity reduction of $1 \mu \mathrm{L}$ saliva of $T$. vitticeps on the composed actions (mean \pm standard error). The area indicates the moment of washing. Ctrl: control.

pump. The weight gain of the insects was similar with both hosts, whereas the total contact time and the number of interruptions tended to be higher when the insect fed on mice (Table III). 
TABLE II

Percentage of food sources in relation to capture sites of Triatoma vitticeps specimens from the district of Itanhomi, Minas Gerais, Brazil

\begin{tabular}{lcccc}
\hline & \multicolumn{3}{c}{ Environment } & Total \\
\cline { 2 - 4 } Host & Intra & Peri & Silvatic & $\mathrm{n}(\%)$ \\
\hline Rodent & $\mathrm{n}(\%)$ & $\mathrm{n}(\%)$ & $3(37)$ & $36(30)$ \\
Bird & $26(29.2)$ & $7(31)$ & - & $30(25)$ \\
Opossum & $25(28)$ & $5(23)$ & $1(13)$ & $8(6.7)$ \\
Human & $4(4.5)$ & $3(14)$ & - & $8(6.7)$ \\
Lizard & $8(9)$ & - & - & $1(0.8)$ \\
Dog & $1(1.1)$ & - & - & $12(10)$ \\
Cattle & $10(11.2)$ & $1(5)$ & $2(25)$ & $1(0.8)$ \\
Armadillo & - & - & $2(25)$ & $2(1.7)$ \\
Did not react & - & $4(18)$ & $21(17.6)$ \\
\hline
\end{tabular}

$a$ : anti-serum tested only on the third testing phase.

TABLE III

Parameters of the feeding behavior, evaluated by cibarial pump eletromyogram, of 2 nd instar nymphs of Triatoma vitticeps on mice and pigeons

\begin{tabular}{lccc}
\hline Parameters & Mice & Pigeon & T test \\
\hline TCT (min) & $26.8 \pm 13.09$ & $19.75 \pm 11.54$ & NS \\
TIT (mg/min) & $2.01 \pm 0.83$ & $2.82 \pm 1.39$ & p $<0.05$ \\
WG (mg) & $46.44 \pm 12.77$ & $41.53 \pm 9.08$ & NS \\
F (contractions/seg) & $2.71 \pm 0.67$ & $4.2 \pm 1.3$ & p $<0.05$ \\
Number of interruptions & $1.43 \pm 1.79$ & $0.5 \pm 0.8$ & NS \\
\hline
\end{tabular}

F: frequency of contraction of the cibarial pump; NS: non-significant; TCT: total contact time; TIT: total ingestion time; WG: weight gain.

Feeding on mice was more difficult for the insects as evidenced by the rhythm of contractions and shape of the electrical signals generated by the cibarial pump during the feeding process. When the contractions were arrhythmic and the electrical signal showed irregular shape ( 2 peaks or intermediary forms between 1 or 2 peaks) a strong noise is observed in the graph of the frequency spectrum through time. This type of signal was constant in $72.7 \%$ of the experiments done on mice (Fig. $2 \mathrm{~A})$. On the other hand, $81.8 \%$ of the cibarial pump measurements from nymphs feeding on pigeons contracted rhythmically and generated regular electrical signals (single peak signals) that generated lower noise on the frequency spectrum through time, as shown in Fig. 2B.

\section{DISCUSSION}

The feeding process of triatomine bugs greatly varies among species and it is influenced by various factors, such as the characteristics of the feeding apparatus and the composition of the saliva, as well as the physiology of the host and the feeding site (Guarneri et al. 2000, 2003, Araujo et al. 2009). Therefore, the capacity to explore available food resources can directly influence the population dynamics and the vectorial capacity of triatominae (Pereira et al. 2006).

Having saliva that reduces the noxious sensation is advantageous because the quantity of blood obtained by triatomines is limited by the irritation caused during the feeding process (Pereira et al. 1995, 1998). Dan et al. (1999) observed that the saliva of Triatoma infestans has an irreversible inhibitory activity on the generation of nervous impulses and this effect may decrease the sensitivity of the region where the insect probes. It has also been demonstrated that Panstrongylus megistus has an inhibitory activity on the generation of nervous impulses (Alves 2007). However, these two triatominae species differ in the reversibility of the inhibition because, contrary to what was observed for T. infestans, the saliva of the $P$. megistus produced a progressive inhibition in the amplitude of action potential in a reversible manner. 
Our results are very similar to those described for the T. infestans saliva. No recovery of the compound action potential amplitude was observed even 30 min after washing the preparation with Locke's solution. This lasting effect might be explained by the high affinity of the active principle of the saliva to the sodium channel or by a similar effect to that observed in response to high concentrations of local anesthetics, which cause a nonreversible block in isolated nerves (Bainton \& Strichartz 1994, Lambert et al. 1994). Thus, we demonstrated that the $T$. vitticeps saliva acts on the nerve endings by inhibiting the generation of nerve impulses and, consequently, the perception of the insect by the host.

Studies on the identification of food sources leads to the discovery of possible natural reservoirs and evaluates the degree of movement of the parasite in the area, contributing to a better understanding of the local epidemiology. Similarly, these studies are important because the natural ecotopes of $T$. vitticeps are unknown. T. vitticeps captured in different sites of ES and RJ showed that the feeding habits of this triatominae species are eclectic (Dias et al. 1989, Gonçalves et al. 2000, Lorosa et al. 2003). The results presented by Dias et al. (1989) showed a marked anthropophilia, with $89.2 \%$ of the antisera reacting to human types, even in the absence of colonization. Our results are pioneers in identifying the food source of T. vitticeps from MG. Again, these insects showed a wide eclecticism in their feeding habits with high incidence of rodents (30\%) and birds (25\%). During the insects capturing, the presence of rodents inside homes was indirectly verified by the observation of feces and by reports of the inhabitants. Besides that, the district was once endemic for the bubonic plague and these synanthropic mammals are abundant in wild environments, which are close to the urbanized areas. Chickens are the most frequent domestic animals and move freely around the houses' backyards, which could have contributed to the results found by the precipitin method. Moreover, considering that the infection is acquired outside of the home environment, the birds are refractory to infection and that there is an intense exchange between wild and artificial environments (Souza et al. 2008), these results suggest a close relationship between $T$. vitticeps and rodents.

Other domestic animals are potential feeding sources of $T$. vitticeps, such as dogs (10\%). These animals are mentioned as important hosts for T. cruzi in various countries of the American continent (Barretto et al. 1980), with Argentina being characterized as the main domestic reservoir (Wisnivesky-Colli et al. 1985, Cohen \& Gürtler 2001). Therefore, dogs have an important epidemiological role for the Chagas disease because the infection of these animals can be a potential link between the domestic and the wild cycles of the disease. Despite the absence of intradomiciliary colonies, the presence of human blood in the digestive tube of the T. vitticeps specimens captured in this environment showed that triatominae adults that invade houses are able to feed on their inhabitants. This highlights the maintenance of an efficient system of entomologic surveillance. In addition, the multiple blood meals found reinforce the fact that this species circulates between wild and artificial environments showing high rates of infection by $T$. cruzi .

The analysis of the electrical activity of the cibarial pump during the feeding process of $T$. vitticeps nymphs allowed the monitoring of its functioning. Similarly, we identified several events such as the bite and the beginning of the exploring phase, the contraction of the pump's dilating muscle, the interruptions of blood pumping and the removal of mouthparts from the host's skin at the end of the feeding. This information and the data on weight gain of the insect allowed the calculation of several parameters of the feeding process.

The duration of the contact is an important factor in the interaction between hematophagous arthropods

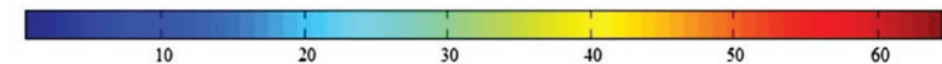

A

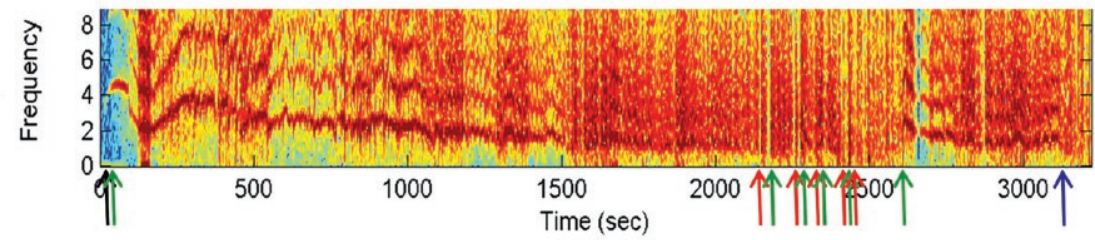

B

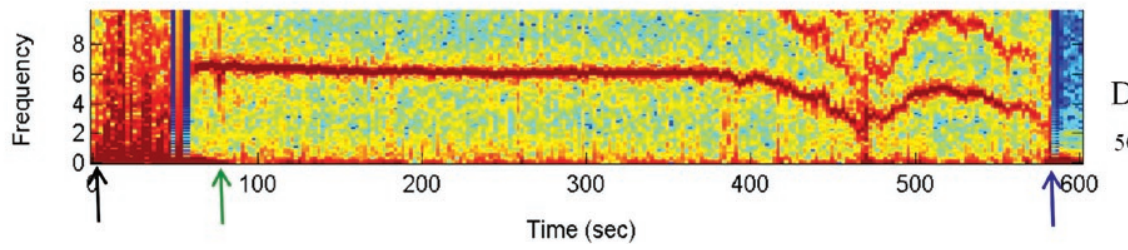

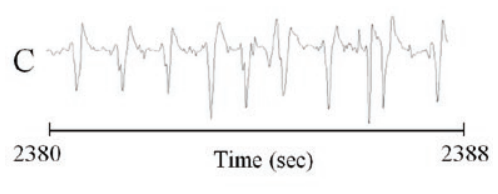

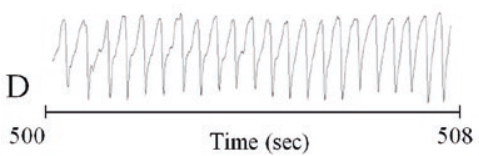

Fig 2: frequency spectrum with time produced by cibarial pump contractions from second instar nymphs of Triatoma vitticeps. Example of noisy spectrum on mice feeding (A) and less noise spectrum on pigeon feeding (B). Observe the detail of electric profile with arrhythmic contractions and irregular signals (C) and with rhythmic contractions and regular signals (D) of spectrum A and B, respectively. The color scale which represents the magnitude of each frequency value is represented at the top. The arrows below each figure represent the moment of the bite (black), the beginning of the engorgement phase or the restart after an interruption (green), engorgement interruption (red) and end of feeding (blue). 
and their hosts because the defensive behavior of hosts can reduce the feeding success or even cause the death of the insect (Guarneri et al. 2003). Therefore, species that possess higher total ingestion rates tend to achieve higher nutritional status and reach higher population densities as occurs in T. infestans and Rhodnius prolixus, the most important vectors of T. cruzi in South and Central America, respectively (Sant'Anna et al. 2001). Our data demonstrated that the nymphs of $T$. vitticeps demand a longer contact time when they feed on mice. According to Guarneri et al. (2000) and Sant'Anna et al. (2001), when nymphs of the same species and the same developmental stage feed on different hosts, the variations in contact time are mainly related to differences in the pump frequency and the number of interruptions. In the present study, the lower blood ingestion rate in mice is mainly related to the lower frequency of contractions of the cibarial pump in this host compared to the pigeon (2.7 and 4.2 contractions/s, respectively). However, the results presented by the precipitin reaction demonstrate that, in natural conditions, both birds and in rodents are important food sources for $T$. vitticeps and that the feeding difficulties are not an obstacle to the use of rodents.

The blood ingestion rate of $T$. vitticeps 2 nd instar nymphs $(2.0 \mathrm{mg} / \mathrm{min})$ was higher than that reported for the same developmental stage of Triatoma brasiliensis and Triatoma pseudomaculata $(1.0$ and $0.4 \mathrm{mg} / \mathrm{min}$, respectively) feeding on mice (Soares et al. 2000). However, $T$. vitticeps is a large triatominae that needs higher quantities of blood to complete its cycle; therefore, it considerably increases the contact time with its hosts. Comparatively, the contact time of $T$. vitticeps 2 nd instar nymphs was higher $(26.8 \mathrm{~min}$ ) than that reported for $T$. brasiliensis and T. pseudomaculata (22.1 and $19.5 \mathrm{~min}$, respectively) (Soares et al. 2000).

During the feedings process of nymphs on mice and pigeons, it was possible to notice the difficulty in obtaining blood due to the irregularity of the electrical signals produced by the cibarial pump, both in frequency and in profile, generating noisy frequency spectra as a function of time. This was especially true in experiments with mice, if we compare the frequency spectra obtained during the $R$. prolixus nymphs feeding on mice when similar experimental conditions were followed (Araujo et al. 2009). Our results corroborate the current knowledge on the biology and the behavior of $T$. vitticeps.

Despite this, it was demonstrated that the saliva of this vector decrease the local sensibility of the hosts. The difficulty in blood obtainment, mainly due to the low contraction frequency of the cibarial pump in mice, could partly explain the feeding eclecticism observed for this triatominae species.

\section{REFERENCES}

Alves CL 2007. Estudo comparativo da ação da saliva de triatomíneos (Heteroptera: Reduviidae) e do predador Belostoma anurum (Heteroptera: Belostomatidae) sobre as preparações de nervo isolado de Rattus novergicus e de vaso dorsal de Rhodnius prolixus, $\mathrm{PhD}$ Thesis, Universidade Federal de Minas Gerais, Belo Horizonte, 96 pp.

Araujo RN, Soares AC, Paim RM, Gontijo NF, Gontijo AF, Lehane MJ, Pereira MH 2009. The role of salivary nitrophorins in the ingestion of blood by the triatomine bug Rhodnius prolixus (Reduviidae: Triatominae). Insect Biochem Mol Biol 39: 83-89.

Bainton CR, Strichartz GR 1994. Concentration dependence of lidocaine-induced irreversible conduction loss in frog nerve. Anesthesiology 81: 657-667.

Barretto MP, Ribeiro RD, Rocha GM 1980. Forest reservoirs and vectors of Trypanosoma cruzi. LXXVIII. Geographical distribution of triatomids in the Paranaíba River valley, Brazil. Rev Bras Malariol Doencas Trop 32: 1-8.

Barros GC, Mayrink W, Abreu Salgado A, Barros RCG, Sessa PA 1975. Contribuição para o conhecimento da doença de Chagas autóctone no estado do Espírito Santo. Rev Inst Med Trop Sao Paulo 17: 319-329.

Bennet-Clark HC 1963. Negative pressures produced in the pharyngeal pump of the blood sucking bug, Rhodnius prolixus. $J$ Exp Biol 40: 223-229.

Cohen JE, Gürtler RE 2001. Modeling household transmission of American trypanosomiasis. Science 293: 694-698.

Cruz JS, Cotta G, Diniz CR, Beirão PS 1994. Partial purification and pharmacological characterization of a neurotoxic fraction isolated from the venom of the spider Lycosa erythrognatha. Braz J Med Biol Res 27: 2653-2659.

Dan A, Pereira MH, Pesquero JL, Diotaiuti L, Beirão PS 1999. Action of the saliva of Triatoma infestans (Heteroptera: Reduviidae) on sodium channels. J Med Entomol 36: 875-879.

Dias JCP, Feitosa VR, Ferraz Filho AN, Rodrigues VLC, Alencar SA, Sessa PA 1989. Fonte alimentar e potencial vetorial de Triatoma vitticeps (Stål, 1859) com relação à doença de Chagas humana no estado do Espírito Santo, Brasil (Hemiptera, Reduviidae). Mem Inst Oswaldo Cruz 84 (Suppl. IV): 165-173.

dos Santos CB, Ferreira AL, Leite GR, Ferreira GEM, Rodrigues AAF, Falqueto A 2005. Peridomiciliary colonies of Triatoma vitticeps (Stål, 1859) (Hemiptera, Reduviidae, Triatominae) infected with Trypanosoma cruzi in rural areas of the state of Espírito Santo, Brazil. Mem Inst Oswaldo Cruz 100: 471-473.

dos Santos CB, Leite GR, Sessa PA, Falqueto A 2006. Dynamics of feeding and defecation in Triatoma vitticeps (Stål, 1859) (Hemiptera, Reduviidae, Triatominae) and its potential in the transmission of Trypanosoma cruzi. Mem Inst Oswaldo Cruz 101: 543-546.

Ferreira E, Souza PA de, Fonseca Filho M da, Rocha I 1986. Nota sobre a distribuição geográfica do Triatoma vitticeps (Stål, 1859) (Hemiptera, Reduviidae) no Estado do Rio de Janeiro, Brasil. Rev Bras Malariol Doencas Trop 38: 11-14.

Gonçalves TC, Rocha DS, Cunha RA 2000. Feeding patterns of Triatoma vitticeps in the state of Rio de Janeiro, Brazil. Rev Saude Publica 34: 348-352.

Gonçalves TCM, Oliveira E, Dias LS, Almeida MD, Nogueira WO, Pires FDA 1998. An investigation on the ecology of Triatoma vitticeps (Stål, 1859) and its possible role in the transmission of Trypanosoma cruzi, in the locality of Triunfo, Santa Maria Madalena municipal district, state of Rio de Janeiro, Brazil. Mem Inst Oswaldo Cruz 93: 711-717.

Guarneri AA, Diotaiuti L, Gontijo NF, Gontijo AF, Pereira MH 2003. Blood-feeding performance of nymphs and adults of Triatoma brasiliensis on human hosts. Acta Trop 87: 361-370.

Guarneri AA, Diotaiuti L, Gontijo NF, Gontijo AF, Pereira MH 2000. Comparison of feeding behaviour of Triatoma infestans, Triatoma brasiliensis and Triatoma pseudomaculata in different hosts by electronic monitoring of the cibarial pump. $J$ Insect Physiol 46: 1121-1127. 
Lambert LA, Lambert DH, Strichartz GR 1994. Irreversible conduction block in isolated nerve by high concentrations of local anesthetics. Anesthesiology 80: 1082-1093.

Lent H, Wygodzinsky P 1979. Revision of the Triatominae (Hemiptera, Reduviidae), and their significance as vectors of Chagas disease. Bull Am Mus Nat Hist 163: 125-520.

Lorosa ES, Andrade RE, Santos SM, Pereira CA 1998. Estudo da infecção natural e da fonte alimentar do Triatoma sordida, (Stål, 1859), (Hemiptera - Reduviidae) na região norte de Minas Gerais, Brasil, através da reação de precipitina. Entomol Vect 5: 13-22.

Lorosa ES, Valente MVM, Cunha V, Lent H, Jurberg J 2003. Foco de doença de Chagas em Arcádia, Estado do Rio de Janeiro, Brasil. Mem Inst Oswaldo Cruz 98: 885-887.

Pereira H, Penido CM, Martins MS, Diotaiuti L 1998. Comparative kinetics of bloodmeal intake by Triatoma infestans and Rhodnius prolixus, the two principal vectors of Chagas disease. Med Vet Entomol 12: 84-88.

Pereira MH, Gontijo NF, Guarneri AA, Sant'Anna MR, Diotaiuti L 2006. Competitive displacement in Triatominae: the Triatoma infestans success. Trends Parasitol 22: 516-520.

Pereira MH, Penido CM, Martins MS, Diotaiuti L 1995. Triatoma infestans is more efficient than Panstrongylus megistus in obtaining blood meals on non anaesthetized mice. Mem Inst Oswaldo Cruz 90: 765-767.

Pinto AFS, Santos UM, Murad V, Lima FEP, Zaganelli FL, Almeida AZ 1969. Doença de Chagas no Estado do Espírito Santo. V Primeiro caso de Chagas diagnosticado no Município de Alfredo Chaves, ES. Rev Soc Bras Med Trop 3: 53.

Pinto AFS, Vieira NER, Milanez MC, Lima Pereira FE, Sessa PA 1986. Doença de Chagas autóctone no Espírito Santo: relato de caso agudo em gestante com transmissão para o feto. Rev Soc Bras Med Trop 19 (Suppl.): 78.

Rossignol PA, Ribeiro JM, Jungery M, Turell MJ, Spielman A, Bailey CL 1985. Enhanced mosquito blood-finding success on parasitemic hosts: evidence for vector-parasite mutualism. Proc Natl Acad Sci USA 82: 7725-7727.

Sant'Anna MR, Diotaiuti L, de Figueiredo Gontijo A, de Figueiredo Gontijo N, Pereira MH 2001. Feeding behaviour of morphologi- cally similar Rhodnius species: influence of mechanical characteristics and salivary function. $J$ Insect Physiol 47: 1459-1465.

Santos UM, Murad V, Chapadeiro E, Pereira FEL 1969a. Doença de Chagas no estado do Espírito Santo. IV- Primeiro caso de Chagas diagnosticado no município de Rio Novo do Sul, ES. Rev Soc Bras Med Trop 3: 52-53.

SantosUM,PintoAFS,ZaganelliFL,AlmeidaAZ, Martins A, Carancho PV, Vieira HJ 1969b. Doença de Chagas no estado do Espírito Santo. II - Inquérito sorológico. Rev Soc Bras Med Trop 3: 51.

Santos UM, Pinto AFS, Zaganelli FL, Almeida AZ, Martins A, Carancho PV, Vieira HJ 1969c. Doença de Chagas no estado do Espírito Santo. III - Vetores do Trypanosoma. Rev Soc Bras Med Trop 3: 51-52.

Schofield CJ 1994. Triatominae. Biology y control, Eurocommunica Publications, West Sussex, 74 pp.

Sessa PA, Carias VRD 1986. Infecção natural de triatomíneos do Espírito Santo por flagelados morfologicamente semelhantes ao Trypanosoma cruzi. Rev Soc Bras Med Trop 19: 99-100.

Silveira AC, Feitosa VR, Borges R 1984. Distribuição de triatomíneos capturados no ambiente domiciliar no período de 1975-1983, no Brasil. Rev Bras Malariol Doencas Trop 36: 15-312.

Siqueira AF 1960. Estudos sobre a reação de precipitina aplicada à identificação do sangue ingerido por triatomíneos. Rev Inst Med Trop Sao Paulo 2: 41-53.

Smith JJ 1979. Effect of diet viscosity on the operation of the pharyngeal pump in the blood-feeding bug Rhodnius prolixus. $J$ Exp Biol 82: 93-104.

Soares RPP, Evangelista LG, Laranja LS, Diotaiuti L 2000. Population dynamics and feeding behavior of Triatoma brasiliensis and Triatoma pseudomaculata, main vectors of Chagas disease in Northeastern Brazil. Mem Inst Oswaldo Cruz 95: 151-155.

Souza RCM, Barbosa SE, Sonoda IV, Azeredo BVM, Romanha AJ, Diotaiuti L 2008. Population dynamics of Triatoma vitticeps (Stål, 1859) in Itanhomi, Minas Gerais, Brazil. Mem Inst Oswaldo Cruz 103: 14-20.

Wisnivesky-Colli C, Gürtler RE, Solarz ND, Lauricella MA, Segura EL 1985. Epidemiological role of humans, dogs and cats in the transmission of Trypanosoma cruzi in a central area of Argentina. Rev Inst Med Trop Sao Paulo 27: 346-352. 